\title{
Keratoconus patients at Jordan University Hospital: a descriptive study
}

This article was published in the following Dove Press journal:

Clinical Ophthalmology

I5 November 2012

Number of times this article has been viewed

Mohammed A Abu Ameerh

Rola M Al Refai

Muawya D Al Bdour

Ophthalmology Department, Jordan University Hospital, Amman, Jordan
Correspondence: Mohammed A Abu Ameerh

PO Box I3046, Amman II942, Jordan

Tel +962799060613

Fax+96265353399

Email mohammd73@yahoo.com
Purpose: To study a sample of keratoconus patients, who were referred to Jordan University Hospital for possible penetrating keratoplasty (PKP), and provide basic epidemiological analysis.

Method: A descriptive study; we reviewed the medical records of 308 keratoconus patients referred for possible PKP. The following parameters were collected and analyzed: sex predilection, age at presentation, best corrected visual acuity, severity, bilaterality of the disease, and its association with vernal catarrh.

Results: Males constituted $61.6 \%$ while females constituted $38.4 \%$ of the study group. The mean age at presentation for males and females was 19.1 and 19.9 years, respectively. The best corrected visual acuity on evaluation was $\leq 6 / 60$ in $60.4 \%$ of males' eyes and $57.9 \%$ of females' eyes; $>6 / 60$ and $<6 / 12$ in $30 \%$ of males' eyes and $28.5 \%$ of females' eyes; and $\geq 6 / 12$ in $9.6 \%$ of males' eyes and $13.6 \%$ of females' eyes. Regarding the severity, $72.3 \%$ of males' eyes and $71.8 \%$ of females' eyes had severe keratoconus; $17.3 \%$ of males' and $28.2 \%$ of females' eyes had moderate keratoconus; and $10.4 \%$ of males' eyes had mild keratoconus, which was not recorded in females. $90.5 \%$ of male patients and $93.2 \%$ of female patients had bilateral disease and vernal catarrh was recorded in $33.7 \%$ of males and $35.6 \%$ of females.

Conclusion: Keratoconus was found to be more prevalent in Jordanian males referred for PKP than females, keeping in mind that this doesn't reflect the real sex predilection in the general population. Males also presented at a younger age. We didn't find any association between gender and bilaterality, nor association with vernal catarrh.

Keywords: Jordan, keratoconus, penetrating keratoplasty, vernal keratoconjunctivitis

\section{Introduction}

Keratoconus is a corneal ectasia characterized by a central and paracentral corneal thinning. Recent investigations suggest that keratoconus may have an inflammatory etiology. ${ }^{1-3}$ Early histopathologic features include thinning and ectasia of the corneal stroma, iron deposition in the epithelial basement membrane, and breaks in Bowman's layer. ${ }^{4}$ Despite intensive clinical and laboratory investigation, its precise etiology is unknown., ${ }^{5,6}$ Keratoconus is mostly an isolated disorder, although several reports describe systemic association with Down syndrome, Leber's congenital amaurosis, and connective tissue disorders such as Turner's syndrome. ${ }^{7,8}$ Atopy and vernal keratoconjunctivitis (VKC) are often cited as being highly associated with keratoconus. ${ }^{9,10}$ Keratoconus causes deterioration in vision as there is a progressive thinning of the cornea with induced myopia and irregular astigmatism that will require rather sequential treatment ranging from glasses to contact lenses to intrastromal corneal rings, and, in many, penetrating keratoplasty (PKP). ${ }^{11,12}$ 
The purpose of our study is to provide the first epidemiological analysis of a large group of keratoconus patients who were referred to Jordan University Hospital (JUH) as cases in need for PKP.

\section{Materials and methods}

We reviewed and analyzed medical records of 308 patients. Those patients were referred and assessed at the ophthalmology department at JUH, a tertiary care centre, between June 2008 and March 2010. Collected data included gender of patients, and age at presentation.

Patients were diagnosed to have keratoconus based on clinical examinations, which included slit lamp assessment and corneal topography using a Pentacam (OCULUS, Wetzlar, Germany). There are many classifications to describe the severity of keratoconus. We have chosen the keratometric classification as it is a simple, and applicable practice at our unit. According to average keratometric readings, eyes were sub classified into: mild keratoconus ( $<48$ diopters), moderate (48-54 diopters), and severe ( $>54$ diopters).

Eyes were assigned to 3 groups according to the best spectacle-corrected visual acuity: the first group included eyes with a visual acuity of $\leq 6 / 60$ (20/200), the second group included eyes with a visual acuity of $>6 / 60(20 / 200)$ and $<6 / 12(20 / 40)$, while the third group was those eyes with visual acuity of $\geq 6 / 12$ (20/40).

Patients who had active or inactive typical signs of VKC were identified. Finally the bilaterality of the disease was looked at and analyzed.

All patients referred to our department for possible PKP between June 2008 and March 2010, and who were diagnosed to have keratoconus based on clinical examination and corneal topography were included in the study.

Patients who underwent corneal grafting in the other eye, those who were characterized with unilateral disease, patients with uncertain age of onset, or those with missing data were excluded from this study.

\section{Statistical analysis}

SPSS version 17 (IBM Corporation, Armonk, NY) was used to perform the statistical analysis. Descriptive statistics (means, standard deviations, and percentages) were used to describe targeted variables. Moreover, Pearson's Chi-square test was carried out to investigate possible correlations.

\section{Results}

A total of 308 medical records were reviewed and analyzed. Out of these, 190 patients $(61.6 \%)$ were males and
118 (38.4\%) were females. Of the 308 records reviewed, we found that 24 patients ( 16 males and 8 females) had undergone PKP in one of their eyes and thus were excluded from certain aspects of analysis. Other missing data encountered were: age at onset, accurate keratometric reading, and visual acuity on evaluation - details will be discussed later - which eventually led to the exclusion of these patients from certain aspects of our analysis; however they were counted in some aspects in which they could fulfill the inclusion criteria.

Of the population comprised of 616 eyes identified with keratoconus, 50 eyes were excluded depending on the criteria above; the remaining 566 eyes were enrolled and used in the analysis. 173 patients $(61.2 \%)$ were males and $110(38.8 \%)$ were females.

The age at presentation ranged from 6-45 years with a mean age for the male group and the female group of 19.1 $(\mathrm{SD}=10.65)$ years and $19.9(\mathrm{SD}=10.69)$ years, respectively. Males presented at a younger age than females. There were 104 male patients (54.7\%) who presented at an age of $<20$ years, while 64 male patients (33.7\%) presented after the age of 20 years. The remaining 22 male patients (11.6\%) could not specify exactly the onset of their disease. As for the female group, 60 female patients (50.8\%) presented before 20 years of age, and 42 females (35.6\%) presented after the age of 20 years, while 16 patients (13.6\%) could not recall the onset of their disease (Table 1).

Regarding the severity of keratoconus on evaluation, we found that $72.3 \%$ of the eyes of male patients and $71.8 \%$ of the eyes of female patients had severe keratoconus and did not benefit from glasses or contact lenses to improve their vision. The percentage of eyes with moderate keratoconus was $17.3 \%$ of males and $28.2 \%$ of females. Although none of the females' eyes had mild keratoconus at time of evaluation, $10.4 \%$ of males eyes had mild keratoconus (Table 1).

The percentage of eyes of male patients that had best corrected visual acuity on evaluation of $\leq 6 / 60$ was $60.4 \%$, while $30 \%$ had visual acuity $>6 / 60$ and $<6 / 12$, and the remaining had a visual acuity $\geq 6 / 12$. On the other hand, the percentage of female patients that had a mean visual acuity on evaluation of $\leq 6 / 60$ was $57.9 \%$, between $6 / 60$ and $6 / 12$ was $28.5 \%$, and $\geq 6 / 12$ was $13.6 \%$.

We did not find any significant association between gender and baseline visual acuity $(P=0.192)$. Furthermore, there was not any significant association between gender and neither bilaterality of the disease nor VKC $(P=0.4)$.

VKC was found in $33.7 \%$ of male patients and $35.6 \%$ of female patients. Out of the 308 patients included in the 
Table I Demographic characteristics of the study population $(n=308$ patients, 616 eyes $)$

\begin{tabular}{|c|c|c|c|c|c|c|c|}
\hline \multirow[t]{2}{*}{ Variable } & \multicolumn{2}{|c|}{ Males } & \multicolumn{2}{|c|}{ Females } & \multicolumn{2}{|l|}{ Total } & \multirow[t]{2}{*}{$P$-value } \\
\hline & 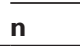 & $\%$ & $\bar{n}$ & $\%$ & $\bar{n}$ & $\%$ & \\
\hline$\overline{\text { Sex }}$ & 190 & $61.6 \%$ & 118 & $38.4 \%$ & 308 & $100 \%$ & \\
\hline Mean age at presentation (SD) & \multicolumn{2}{|c|}{19.1 years $(10.65)$} & \multicolumn{2}{|c|}{19.9 years $(10.69)$} & & & $P<0.05$ \\
\hline Age at presentation & $190 \mathrm{pt}$ & & 118 & & $308 \mathrm{pt}$ & & \\
\hline$<20$ yrs & 104 & $54.7 \%$ & 60 & $50.8 \%$ & 164 & $53.2 \%$ & \\
\hline$>20 \mathrm{yrs}$ & 64 & $33.7 \%$ & 42 & $35.6 \%$ & 106 & $34.4 \%$ & \\
\hline Unspecified & 22 & $11.6 \%$ & 16 & $13.6 \%$ & 38 & $12.4 \%$ & \\
\hline Severity of $K C$ on evaluation & $346 \mathrm{e}$ & & 220 & & $566 \mathrm{e}$ & & $P>0.05^{*}$ \\
\hline Severe $(K>54 D)$ & 250 & $72.3 \%$ & 158 & $71.8 \%$ & 408 & $72.1 \%$ & \\
\hline Moderate $(\mathrm{K}=48-54 \mathrm{D})$ & 60 & $17.3 \%$ & 62 & $28.2 \%$ & 122 & $21.6 \%$ & \\
\hline Mild $(K<48 \mathrm{D})$ & 36 & $10.4 \%$ & 0 & 0 & 36 & $6.3 \%$ & \\
\hline Visual acuity on evaluation* & $364 \mathrm{e}$ & & 228 & & $592 \mathrm{e}$ & & $P>0.192$ \\
\hline$\leq 6 / 60$ & 220 & 60.4 & 132 & $57.9 \%$ & 352 & $59.5 \%$ & \\
\hline$>6 / 60$ to $<6 / 12$ & 109 & $30 \%$ & 65 & $28.5 \%$ & 174 & $29.4 \%$ & \\
\hline$\geq 6 / 12$ & 35 & $9.6 \%$ & 31 & $13.6 \%$ & 66 & $11.1 \%$ & \\
\hline Bilaterality on evaluation & $190 \mathrm{pt}$ & & 118 & & $308 \mathrm{pt}$ & & $P>0.4$ \\
\hline $\begin{array}{l}\text { Number of patients with } \\
\text { bilateral disease from the } \\
\text { total number of patients }\end{array}$ & 172 & $90.5 \%$ & 110 & $93.2 \%$ & 282 & $91.6 \%$ & \\
\hline VKC on evaluation: & $190 \mathrm{pt}$ & & 118 & & $308 \mathrm{pt}$ & & \\
\hline $\begin{array}{l}\text { Number of patients with } \\
\text { bilateral disease from the } \\
\text { total number of patients }\end{array}$ & 64 & $33.7 \%$ & 42 & $35.6 \%$ & 106 & $34.4 \%$ & \\
\hline
\end{tabular}

Notes: *Eyes with corneal grafts and unaffected eyes were excluded from the calculation ( 34 eyes in males and 16 eyes in females). *Eyes with corneal grafts were excluded from the calculation ( 16 eyes in males and 8 in females).

Abbreviations: e, eyes; D, diopter; K, keratometric power; KC, keratoconus; $n$, number of patients; pt, patient; SD, standard deviation; VKC, vernal keratoconjunctivitis.

study, bilaterality of the disease was found in $90.5 \%$ of male patients and $93.2 \%$ of female patients.

\section{Discussion}

Keratoconus is described as a rare disease with considerable variation in its prevalence with estimates ranging from $4 / 100,000$ to $600 / 100,000 .^{2}$ Kennedy et a ${ }^{12}$ in 1986 reported a prevalence rate of 54.5/100,000 in the population of Olmsead County in Minnesota which is consistent with reports from others. ${ }^{2,13-16}$ In 1998 Rabinowitz reported the prevalence of keratoconus to vary with most estimates being between 50 and 230 per 100,000 in the general population. ${ }^{2}$ In our paper, we could not comment on the prevalence of keratoconus as we only studied the medical records of those patients referred to JUH as possible candidates for corneal graft surgery.

Keratoconus was found to be responsible for $5 \%$ of unilateral and bilateral blindness in patients over 20 years of age in a hospital based study of causes of blindness among adult Jordanians. ${ }^{17}$ Moreover, in a study regarding the visual outcome after PKP at JUH (1979-1998), it was found that keratoconus was the most common indication for PKP in Jordan, with a percentage of $65.6 \%{ }^{18}$ Therefore, we viewed keratoconus as a serious problem and decided to gather and analyze data regarding keratoconus patients referred for possible PKP, aiming to produce organized epidemiological records about this group of patients in Jordan.

Many previous reports have conceded that keratoconus occurs more frequently in females than males: Fox in 1910, Hansell and Sweet in 1903, and Wood and Woodruff in 1907 showed a preponderance of women sufferers. ${ }^{19-21}$ Sainai et al in their study of keratoconus in Asian eyes in India in 2003, reported that females slightly outnumbered males. ${ }^{22}$ Other recent studies, on the other hand, have found that the prevalence is actually higher in males or that there was no significant difference. ${ }^{19,23-29}$ Rabinowitz in a major review of keratoconus in 1998 reported no sex predilection in keratoconus. ${ }^{2}$ Kennedy et al in a 48 -year clinical trial of keratoconus epidemiology found the mean annual incidence rate to be greater among males, but this difference was not statistically significant. ${ }^{12}$ The figures in our study have reflected a male preponderance of patients referred for PKP (61.6\%), which is statistically significant $(P<0.05)$.

Keratoconus classically presents at puberty and carries a progressive course throughout the third and fourth decades of life. ${ }^{2}$ Sainai et al reported that approximately half of the patients in their study of keratoconus in Asian patients presented before the age of 20 years whereas in the CLEK study only $4 \%$ presented before the age of 20 years. ${ }^{22,23}$ 
Tufts et al in their study of 2723 patients with keratoconus had a mean age at diagnosis of 22.4 years for males (range $=8-75$ years), and 23.3 years (range $=8-61$ years) for females. ${ }^{30}$ Other studies showed variable age at presentation, mostly in the second to third decades of life..$^{28,31,32}$

It is more usual for the condition to have advanced to a stage when ordinary spectacles fail to provide reasonable acuity before the patient is referred to the ophthalmologist. It is, therefore, difficult to determine precisely when the abnormality started. Generally, one is dependent on the patient's memory. In our study the mean age at presentation for males was $19.1(\mathrm{SD}=10.65)$ years and $19.9(\mathrm{SD}=10.69)$ years for females with a range of 6-45 years. In total, $53.2 \%$ of the patients registered at our eyes bank were $<20$ years, and $34.4 \%$ presented at age $>20$ years. The remaining patients could not recall the exact onset of their disease. Only $7.5 \%$ presented after the age of 40 years.

Keratoconus is a bilateral but asymmetrical disease. ${ }^{23}$ It usually develops in one eye and after a variable time, which may reach up to 5-6 years, the second eye develops the disease. ${ }^{10,24,25}$ The reported incidence of unilaterality of keratoconus varies from $14.4 \%-41 \%{ }^{1,12,26,29,33,34}$ Results of our study were consistent with the previous studies where $90.5 \%$ of male patients, and $93.2 \%$ female patients, had bilateral disease at time of presentation. In total, out of 308 patients, $91.6 \%$ showed bilateral disease.

According to the keratometric classification of the disease, $72.3 \%$ of the males' eyes had severe keratoconus, $17.3 \%$ had moderate disease, and the remaining $10.4 \%$ had a mild form. Most of the females' eyes, on the other hand, had severe keratoconus (71.8\%) and the remaining eyes $(28.2 \%)$ were found to have moderate keratoconus while none had the mild form of the disease. There was no statistically significant relationship between gender and severity $(P>0.05)$.

The authors feel the cultural background of Jordan, where males represent the majority of the workforce and are the main financial provider for their families, and, according to the latest census performed in 2004, a sex ratio of males to females of $1.096,{ }^{35}$ could account for the discrepancy in the percentages at presentation, as males tend to seek more medical care in larger numbers and at an earlier age. To be able to find the actual prevalence and sex predilection, a national survey is needed.

Atopy has been always described as highly associated with keratoconus. ${ }^{2,10,36-38}$ Rahi $^{9}$ first drew attention to the wide variety of conditions associated with keratoconus and Gonzales ${ }^{38}$ was the first to mention the association between keratoconus and VKC. This clinical impression was later substantiated by immunological disturbances such as significantly raised levels of total or specific IgE. ${ }^{5}$ In 1988 , Khan et al reported a $7 \%$ incidence of keratoconus in a study of 530 patients with VKC. ${ }^{39}$ In our report there were $33.7 \%$ of male patients and $35.6 \%$ of female patients who showed either active signs of VKC or gave a related history. These patients, who in total represent 106 patients (34.4\%), had received or were still receiving regular medications as antihistamines, steroids, or mast cell stabilizers.

Comparing our study results from the studies mentioned, although we found male predominance for keratoconus, some studies showed female predominance while others did not. We also found a higher percentage of bilateral disease and association with vernal catarrh in comparison with other reports. Regarding age at presentation, most of our patients presented before the age of 20 years which is consistent with what was mentioned in the study literature.

In conclusion, Keratoconus was found to be more prevalent in Jordanian males than females, keeping in mind that this doesn't reflect the real sex predilection in the general population, as this study presents only patients referred to our department for PKP. Males also presented at a younger age than females. There was no statistically significant difference between both sexes regarding bilaterality of disease and association with vernal catarrh.

Although a sufficient sample quantity was studied, it is recommended to conduct further prospective studies which include patients from other districts and cities for greater representation of the keratoconus population in Jordan.

\section{Disclosure}

The authors report no conflicts of interest in this work. No financial support was received for this submission. These findings have not been previously presented.

\section{References}

1. Krachmer JH, Feder RS, Belin MW. Keratoconous and related non inflammatory corneal thinning disorders. Surv Ophthalmol. 1984;28(4):293-322.

2. Rabinowitz YS. Keratoconous. Surv Ophthalmol. 1998;42(4): 297-319.

3. Balasubramanian SA, Pye DC, Willcox MD. Are proteinases the reason for keratoconus? Curr Eye Res. 2010;35(3):185-191.

4. Fernandes BF, Logan P, Zajdenweber ME, Santos LN, Cheema DP, Burnier MN Jr. Histopathological study of 49 cases of keratoconus. Pathology. 2008;40(6):623-626.

5. Kemp EG, Lewis EJ. Immunoglobulin patterns in keratoconus with particular reference to total and specific IgE levels. Br J Ophthalmol. 1982;66(11):717-720.

6. Karseras AG, Ruben M. Aetiology of keratoconus. Br J Ophthalmol. 1976;60(7):522-525. 
7. Ozcan AA, Ersoz TR. Severe acute corneal hydrops in a patient with Down syndrome and persistent eye rubbing. Ann Ophthalmol (Skokie). 2007;39(2):158-160.

8. Macsai M, Maguen E, Nucci P. Keratoconus and Turner's syndrome. Cornea. 1997;16(5):543-546.

9. Rahi A, Davies P, Ruben M, Lobascher D, Menon J. Keratoconus and coexisting atopic disease. Br J Ophthalmol. 1977;61(12):761-764.

10. Totan Y, Hepşen IF, Cekiç O, Gündüz A, Aydin E. Incidence of keratoconus in subjects with vernal keratoconjunctivitis: a videokeratographic study. Ophthalmology. 2001;108(4):824-827.

11. Hall KG. A Comprehensive Study of Keratoconus. Brit J Physiol Opt. 1963;20:215-256.

12. Kennedy RH, Bourne WM, Dyer JA.A 48-year clinical and epidemiologic study of keratoconus. Am J Ophthalmol. 1986;101(3):267-273.

13. Franceschetti A. Keratoconus. In: King JH, McTigue JW, editors. The Cornea World Congress: papers. Washington: Butterworths; 1965: $152-168$.

14. Hofstetter HW. A keratoscopic survey of 13,395 eyes. Am J Optom Arch Am Acad Optom. 1959;36(1):3-11.

15. Grünauer-Kloevekorn C, Duncker GI. Keratoconus: epidemiology, risk factors and diagnosis. Klin Monbl, Augenheilkd. 2006;223(6): 493-502.

16. Nielsen K, Hjortdal J, Aagaard Nohr E, Ehlers N. Incidence and prevalence of keratoconus in Denmark. Acta Ophthalmol Scand. 2007;85(8):890-892.

17. Al-Bdour MD, Al-Till MI, Abu-Khader IB. Causes of blindness among adult Jordanians: a hospital-based study. European Journal of Ophthalmology. 2002;12(1):5-10.

18. Al-Till M. Visual outcome of Penetrating keratoplasty at Jordan University Hospital (1979-1998). Jordan Medical Journal. 2004;38(2):33-36.

19. Fox LW. A Practical Treatise on Ophthalmology. New York: D. Appleton; 1910:231: Chapter VII diseases of the cornea.

20. Hansell HF, Sweet WM. Diseases of the Eye. New York: The Macmillan Company; 1903:229.

21. Wood CA, Woodruff TA. The Commoner Diseases of the Eye: How to Detect and how to Treat Them. Chicago: W.T. Keener; 1904: chapter, The commoner diseases of the cornea:228-229.

22. Sainai JS, Saroha V, Singh P, Sukhija JS, Jain AK. Keratoconus in Asian eyes at a tertiary eye care facility. Clin Exp Optom. 2004;87(2):97-101.

23. Zadnik K, Barr JT, Gordon MO, Edrington TB. Biomicroscopic signs and disease severity in keratoconus. Collaborative Longitudinal Evaluation of Keratoconus (CLEK) Study Group. Cornea. 1996;15(2): 139-146.

24. Lee LR, Hirst LW, Readshaw G. Clinical detection of unilateral keratoconus. Aust N Z J Ophthalmol. 1995;23(2):129-133.
25. Rabinowitz YS, Nesburn AB, McDonnell PJ. Videokeratography of the fellow eye in unilateral keratoconus. Ophthalmology. 1993;100(2): $181-186$.

26. Lass JH, Lembach RG, Park SB, et al. Clinical management of keratoconus. A multicenter analysis. Ophthalmology. 1990;97(4): 433-445.

27. Bariah MA, Mustafa A, Srijit D, Norhani M. Ethnicity Related to Keratoconus. Internat Medi Jour. 2011;18(3):233-236.

28. Fatima T, Acharya MC, Mathur U, Barua P. Demographic profile and visual rehabilitation of patients with keratoconus attending contact lens clinic at a tertiary eye care centre. Cont Lens Anterior Eye. 2010;33(1): 19-22.

29. Weed KH, MacEwen CJ, Giles T, Low J, McGhee CN. The Dundee University Scottish Keratoconus study: demographics, corneal signs, associated diseases, and eye rubbing. Eye (Lond). 2008;22(4): 534-541.

30. Tufts SJ, Moodaley LC, Gregory WM, Davison CR, Buckley RJ. Prognostic factors for the progression of keratoconus. Ophthalmology. 1994;101(3):439-447.

31. Sharma R, Titiyal JS, Prakash G, Sharma N, Tandon R, Vajpayee RB. Clinical profile and risk factors for keratoplasty and development of hydrops in north Indian patients with keratoconus. Cornea. 2009;28(4):367-370.

32. Olivares Jiménez JL, Guerrero Jurado JC, Bermudez Rodriguez FJ, Serrano Laborda D. Keratoconus: age of onset and natural history. Optom Vis Sci. 1997;74(3):147-151.

33. Macsai MS, Varley GA, Krachmer JH. Development of keratoconus after contact lens wear. Patient characteristics. Arch Ophthalmol. 1990;108(4):534-538

34. Yildiz EH, Diehl GF, Cohen EJ, Hammersmith KM, Laibson PR, Rapuano CJ. Demographics of patients older than 50 years with keratoconus. Eye Contact Lens. 2009;35(6):309-311.

35. Statistical Yearbook, 2004. Department of Statistics, the Hashemite Kingdom of Jordan.

36. Galin MA, Berger R. Atopy and keratoconus. Am J Ophthalmol. 1958;45(6):904-906.

37. Spencer WH, Fisher JJ. The association of keratoconus with atopic dermatitis. Am J Ophthalmol. 1959;47(3):332-344.

38. Gonzales J, de J. Keratoconus consecutive to vernal conjunctivitis. Am J Ophthalmol. 1920;3:127-128.

39. Khan MD, Kundi N, Saeed N, Gulab A, Nazeer AF. Incidence of keratoconus in spring catarrh. Br J Ophthalmol. 1988;72(1):41-43.
Clinical Ophthalmology

\section{Publish your work in this journal}

Clinical Ophthalmology is an international, peer-reviewed journal covering all subspecialties within ophthalmology. Key topics include: Optometry; Visual science; Pharmacology and drug therapy in eye diseases; Basic Sciences; Primary and Secondary eye care; Patient Safety and Quality of Care Improvements. This journal is indexed on Submit your manuscript here: http://www.dovepress.com/clinical-ophthalmology-journa

\section{Dovepress}

PubMed Central and CAS, and is the official journal of The Society of Clinical Ophthalmology (SCO). The manuscript management system is completely online and includes a very quick and fair peer-review system, which is all easy to use. Visit http://www.dovepress.com/ testimonials.php to read real quotes from published authors. 